\title{
Chronic subdural hematoma: a systematic review and meta-analysis of surgical procedures
}

\author{
A systematic review \\ *Weiming Liu, M.D., ${ }^{1}$ Nicolats A. Bakker, M.D., Ph.D., ${ }^{2}$ \\ and Rob J. M. Groen, M.D., Ph.D. ${ }^{2}$
}

${ }^{1}$ Department of Neurosurgery, Beijing Tiantan Hospital, Capital Medical University, China; and ${ }^{2}$ Department of Neurosurgery, University Medical Center Groningen, University of Groningen, The Netherlands

Object. In this paper the authors systematically evaluate the results of different surgical procedures for chronic subdural hematoma (CSDH).

Methods. The MEDLINE, Embase, Cochrane Central Register of Controlled Trials, and other databases were scrutinized according to the PRISMA (Preferred Reporting Items for Systematic Reviews and Meta-Analysis) statement, after which only randomized controlled trials (RCTs) and quasi-RCTs were included. At least 2 different neurosurgical procedures in the management of chronic subdural hematoma (CSDH) had to be evaluated. Included studies were assessed for the risk of bias. Recurrence rates, complications, and outcome including mortality were taken as outcome measures. Statistical heterogeneity in each meta-analysis was assessed using the $\mathrm{T}^{2}$ (tau-squared), $\mathrm{I}^{2}$, and chi-square tests. The DerSimonian-Laird method was used to calculate the summary estimates using the fixed-effect model in meta-analysis.

Results. Of the 297 studies identified, 19 RCTs were included. Of them, 7 studies evaluated the use of postoperative drainage, of which the meta-analysis showed a pooled OR of 0.36 (95\% CI $0.21-0.60 ; \mathrm{p}<0.001)$ in favor of drainage. Four studies compared twist drill and bur hole procedures. No significant differences between the 2 methods were present, but heterogeneity was considered to be significant. Three studies directly compared the use of irrigation before drainage. A fixed-effects meta-analysis showed a pooled OR of 0.49 (95\% CI $0.21-1.14 ; \mathrm{p}=0.10)$ in favor of irrigation. Two studies evaluated postoperative posture. The available data did not reveal a significant advantage in favor of the postoperative supine posture. Regarding positioning of the catheter used for drainage, it was shown that a frontal catheter led to a better outcome. One study compared duration of drainage, showing that 48 hours of drainage was as effective as 96 hours of drainage.

Conclusions. Postoperative drainage has the advantage of reducing recurrence without increasing complications. The use of a bur hole or twist drill does not seem to make any significant difference in recurrence rates or other outcome measures. It seems that irrigation may lead to a better outcome. These results may lead to more standardized procedures. (http://thejns.org/doi/abs/10.3171/2014.5.JNS132715)

\section{KeY Words • chronic subdural hematoma • review • meta-analysis • traumatic brain injury}

$\mathrm{C}$ HRONIC subdural hematoma (CSDH) is a frequently encountered neurosurgical condition, especially in the elderly, with an incidence of 58/100,000 persons a year in people 70 years of age or older. ${ }^{21} \mathrm{Al}-$ though CSDH is one of the most commonly encountered conditions in neurosurgery, no consensus yet exists regarding the optimal surgical technique to treat the CSDH. All surgical strategies aim at decompression of the cerebral hemisphere and to prevent recurrence of CSDH, with minimal morbidity and mortality. Recurrence rates, however, can be high, with reported rates up to $33 \% .{ }^{35}$ It has already been shown by Santarius et al. that drainage after surgical evacuation of the hematoma likely leads to a better outcome. ${ }^{28}$ Besides drainage, other questions

\footnotetext{
Abbreviations used in this paper: $\mathrm{CSDH}=$ chronic subdural hematoma; M-H = Mantel-Haenszel; RCT = randomized controlled trial.

* Drs. Liu and Bakker contributed equally to this work.
}

that remain imminent are the use of a regular bur hole or the use of a twist drill, the use of irrigation, the optimal duration of drainage, postoperative posture, and optimal location of the catheter used for drainage. In the available literature, results are inconsistent. In view of the aforementioned factors we aimed to perform an extensive systematic review addressing these issues.

\section{Methods}

Study Inclusion

A systematic search was performed in MEDLINE, Embase, the Cochrane Central Register of Controlled Trials (CENTRAL, The Cochrane Library 2012, Issue 1), LILACS (Latin American and Caribbean Center on

This article contains some figures that are displayed in color online but in black-and-white in the print edition. 

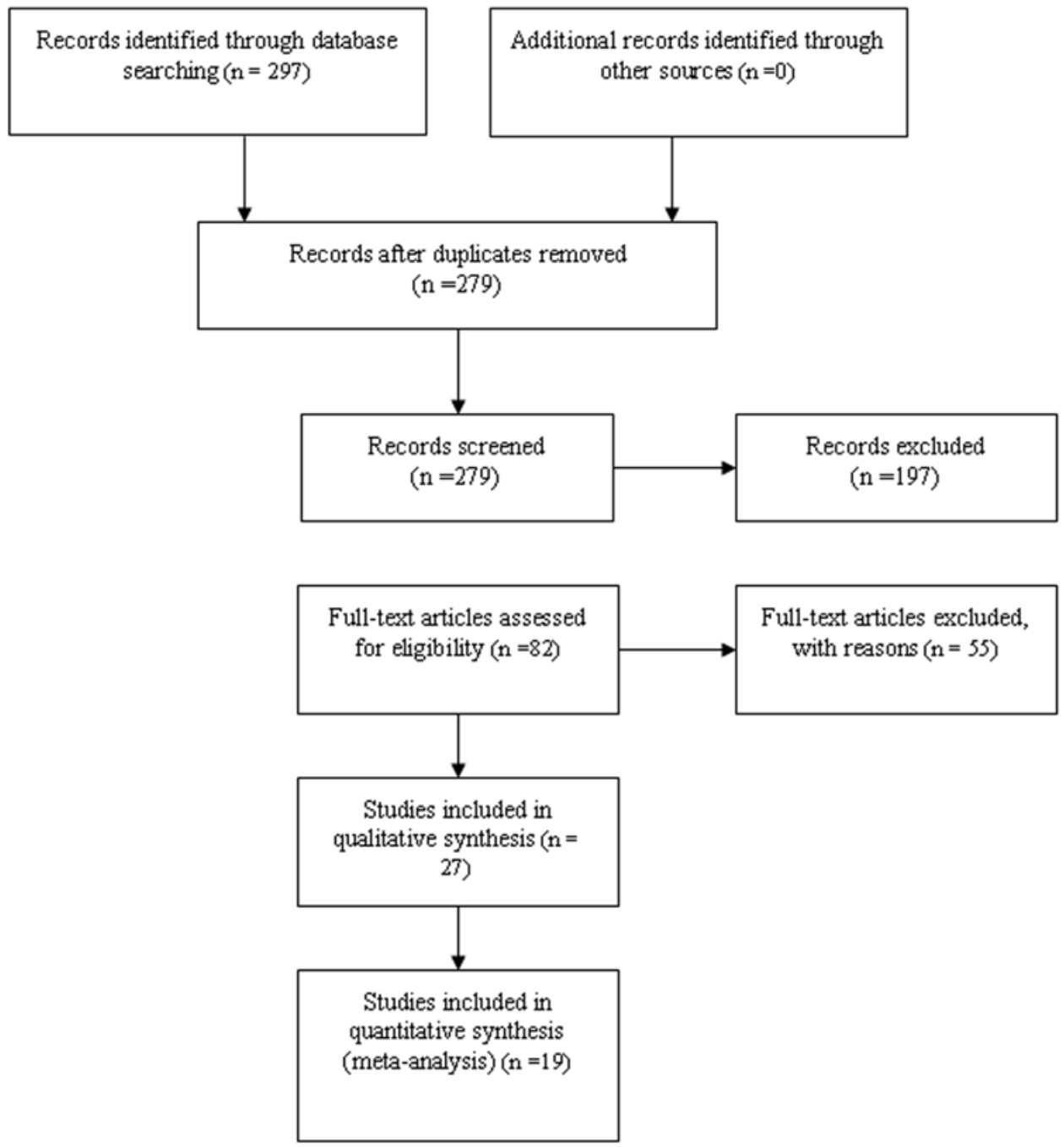

FIG. 1. Flowchart according to the PRISMA statement.

Health Sciences Information), CMB (Chinese Biomedical Database), and Google Scholar. The last search was conducted on December 1, 2013, and went back as far as data were available. The PRISMA (Preferred Reporting Items for Systematic Reviews and Meta-Analysis) statement was followed. In addition, references of the included studies were scrutinized for additional studies. The Cochrane Highly Sensitive Search Strategy for identifying randomized trials was used. ${ }^{9}$ No language restrictions were applied. The following search terms were used: "chronic subdural hematoma"[All Fields] OR "hematoma, subdural, chronic"[MeSH Terms] OR ("hematoma"[All Fields] AND "subdural"[All Fields] AND "chronic"[All Fields]) OR "chronic subdural hematoma"[All Fields] OR ("chronic"[All Fields] AND "subdural"[All Fields] AND "hematoma"[All Fields]).

After careful evaluation, only RCTs and quasi-RCTs (pseudo-random) were included. Quasi-RCTs were defined as allocation by date of birth, day of the week, medical record number, and month of the year, among others. The included studies at least had to focus on 2 different neurosurgical procedures to treat $\mathrm{CSDH}$ : twist drill or bur hole, drainage or not, irrigation or not, catheter location, duration of drainage, and/or postoperative posture. A bur hole in general leads to a craniostomy opening of approximately $10 \mathrm{~mm}$; a twist-drill craniostomy may be a hole as small as $1 \mathrm{~mm}$ up to $5 \mathrm{~mm}$.

\section{Outcome Measures}

Recurrence rates, complication rates, and outcome including mortality were used as outcome measures. Chronic SDH recurrence was defined as the presence of symptoms attributable to an ipsilateral hematoma and with the presence of a hematoma on a CT scan, within 6 months after the initial surgical procedure. The following conditions were considered to be complications: surgical site infections (subdural empyema, incision infections, and meningitis), infection in other parts of the body (pneumonia, urinary tract infections, and gastrointestinal infections), intracranial hemorrhage independent from CSDH (parenchymal hemorrhage and acute subdural hematoma), seizure, other organ complications (arrhythmia, myocardial infarction, and renal failure), and electrolyte imbalance. Pneumocephalus was not considered a com- 


\section{Chronic SDH and surgical procedures}

TABLE 1: Characteristics of included studies*

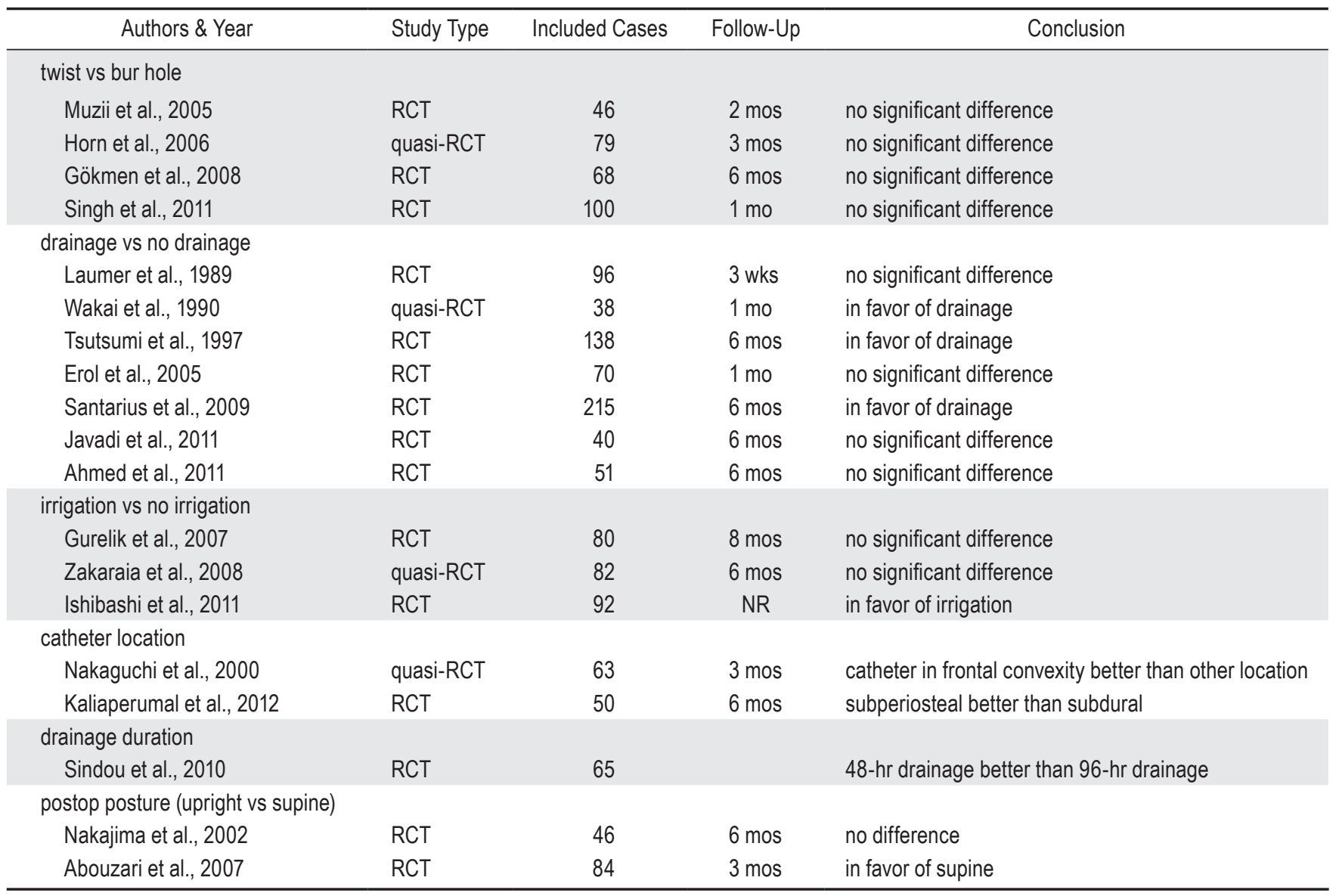

* $\mathrm{NR}=$ not reported.

plication, in contrast with symptomatic (tension) pneumocephalus, which was considered a complication.

A Glasgow Outcome Scale score ${ }^{16}$ of $4-5$ or a modified Rankin Scale score of $0-3$ was considered a favorable outcome. Operative mortality was defined as any death, regardless of cause, occurring 1) within 30 days after surgery in or out of the hospital or 2) after 30 days during the same hospitalization subsequent to the operation. ${ }^{17}$

\section{Selection of Studies}

We each independently selected trials for inclusion in the review and cross-checked the outcome data. Two authors (W.L. and N.A.B.) independently extracted and cross-checked the outcome data. Disagreements were solved by discussion.

\section{Assessment of Risk of Bias in Included Studies}

Two review authors (W.L. and N.A.B.) independently assessed the risk of bias of the included trials according to the Cochrane Handbook for Systematic Reviews of Interventions ${ }^{9}$ based on the following 6 domains with the rating of low risk of bias, high risk of bias, and uncertain risk of bias: random sequence generation, allocation concealment, blinding, incomplete outcome data, selective reporting, and other bias. Other criteria included the prognostic balance between the 2 treatment arms and the completeness and length of follow-up (6 months).

\section{Statistics: Assessment of Heterogeneity and Reporting Biases in Meta-Analysis}

Statistical heterogeneity in each meta-analysis was assessed using the $\mathrm{T}^{2}$ (tau-squared), $\mathrm{I}^{2}$, and chi-square tests. Heterogeneity was considered substantial if $\mathrm{T}^{2}>$ 0 or $\mathrm{I}^{2}$ was greater than $30 \%$ or in case of a p value $<$ 0.10 in the chi-square test for heterogeneity. When reporting bias was suspected, we attempted to contact study authors, asking them to provide missing outcome data. When this was not possible and the missing data were considered to introduce serious bias, the impact of these studies in the overall assessment of results was analyzed by a sensitivity analysis. In case of 5 or more studies in a meta-analysis, reporting biases (such as publication bias) were analyzed using funnel plots. Publication bias is defined as the phenomenon in which statistically significant results are more likely to be published and cited. When an unbiased sample of trials performed is studied with a funnel plot, the observed effect sizes should range symmetrically around the true effect size, which will be most accurately estimated by the largest trials, resulting in a symmetrical plot shaped like an inverted funnel. 
If enough studies on a specific topic were present, a meta-analysis was performed using Review Manager 5.1 (The Nordic Cochrane Centre, The Cochrane Collaboration, 2011). The DerSimonian-Laird method was used to calculate the summary estimate ${ }^{4}$ using the fixed-effect model.

\section{Results}

\section{Search Results}

Overall, the literature searches identified 297 clinical trials addressing CSDH (Fig. 1). Of the titles and abstracts screened, 82 relevant full papers were retrieved and assessed in detail. A total of 27 RCTs and quasiRCTs were related to CSDH. We excluded 8 RCTs, 1 because of repeated publishing in another language, ${ }^{12} 1$ because not enough data were provided, ${ }^{6}$ and 1 because prospectively collected results were compared with historical controls. ${ }^{22}$ Four other studies were excluded because different nonsurgical treatments were applied in the control group. ${ }^{10,20,27,29}$ Therefore, 19 studies were included in this review (Table 1). Among these trials, 4 compared twist drill with bur hole procedures, 7 compared drainage versus no drainage postoperatively, 3 compared irrigation versus no irrigation, 2 compared catheter location, 2 compared postoperative posture, and 1 compared duration of drainage.

\section{Assessment of Risk of Bias of the Included Studies}

Details of assessment of risk of bias in included studies are shown in Fig. 2. Although some trials were declared randomized, their random sequence generation and allocation concealment were not clear. If the study was not complete-length of follow-up was less than 6 months or important data (such as recurrence, complications, outcome, and mortality) were not present-this study was considered incomplete regarding outcome data.

\section{Postoperative Drainage}

Seven trials compared drainage versus no drainage after a bur hole procedure. Three of them concluded the use of drainage to be superior. ${ }^{28,34,35}$ The other 4 trials did not identify significant differences in outcome..$^{2,5,15,23} \mathrm{In}$ all 7 trials, reoperation rates were considered recurrence rates. However, indications for reoperation were different. Laumer et al. ${ }^{23}$ defined recurrent CSDH as either worsening of neurological symptoms or hematoma increase on CT. The other 6 trials used the presence of both worsening of neurological symptoms and hematoma increase on $\mathrm{CT}$ as an indication for reoperation. As such, the study by Laumer et al. was excluded from the analysis. The study by Erol et al. ${ }^{5}$ used a follow-up of 1 month; the other 5 trials had a follow-up of 6 months.

These 6 trials included 523 patients. There were 23 cases of recurrent CSDH among 273 patients $(8.4 \%)$ with a closed drainage system in contrast with 54 cases of recurrence CSDH of 259 patients without a closed drainage system (20.8\%). A fixed-effects meta-analysis showed a pooled OR of 0.36 (95\% CI $0.21-0.60 ; \mathrm{p}<0.001)$, indicating a significant benefit for the use of a closed drainage

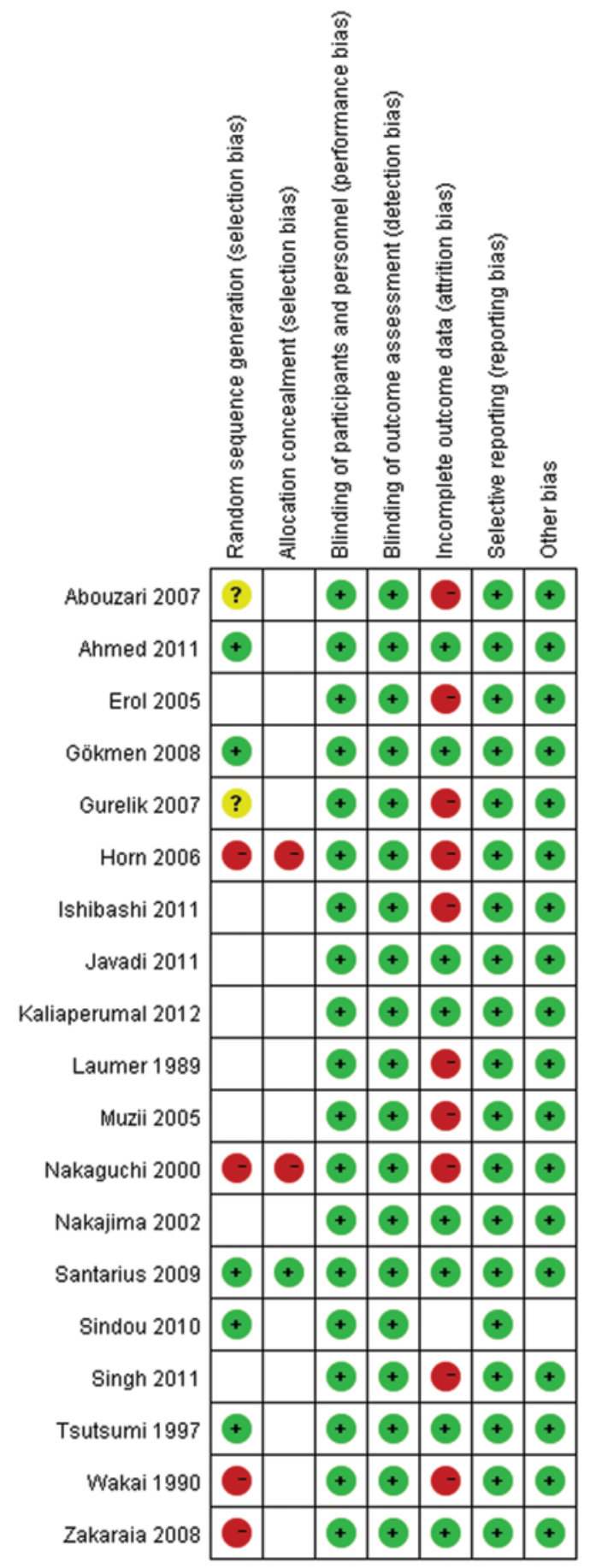

Fig. 2. Risk of bias summary showing our judgments about each risk of bias item for each included study. Green plus sign = low risk; red minus sign = high risk; yellow question mark = not reported; blank $=$ unclear risk.

system (Fig. 3A). There was no indication of heterogeneity between the results of the different trials $\left(\mathrm{p}=0.42 ; \mathrm{I}^{2}=\right.$ $0 \%$ ). A funnel plot was used to test for publication bias in our meta-analysis. Figure 4 shows that the trials in metaanalysis seem approximately symmetric in both analyses.

The study by Tsutsumi et al..$^{34}$ did not report complications, while Wakai et al. ${ }^{35}$ reported complications with- 


\section{Chronic SDH and surgical procedures}

\begin{tabular}{|c|c|c|c|c|c|c|c|c|c|c|}
\hline A & with drainag & tem & without draine & tem & & Odds Ratio & & Odds & s Ratio & \\
\hline Study or Subaroup & Events & Total & Events & Total & Weiaht & M-H, Fixed, $95 \% \mathrm{Cl}$ & Year & M-H, Fixe & red, $95 \% \mathrm{Cl}$ & \\
\hline Wakai 1990 & 1 & 20 & 6 & 18 & $11.9 \%$ & $0.11[0.01,0.99]$ & 1990 & & & \\
\hline Tsutsumi 1997 & 2 & 65 & 9 & 53 & $19.1 \%$ & $0.16[0.03,0.75]$ & 1997 & & & \\
\hline Erol 2005 & 5 & 35 & 6 & 35 & $10.2 \%$ & $0.81[0.22,2.93]$ & 2005 & & & \\
\hline Santarius 2009 & 10 & 108 & 26 & 107 & $47.1 \%$ & $0.32[0.14,0.70]$ & 2009 & - & & \\
\hline Ahmed 2011 & 4 & 25 & 6 & 26 & $9.8 \%$ & $0.63[0.16,2.59]$ & 2011 & & & \\
\hline Javadi 2011 & 1 & 20 & 1 & 20 & $1.9 \%$ & $1.00[0.06,17.18]$ & 2011 & & & \\
\hline Total (95\% Cl) & & 273 & & 259 & $100.0 \%$ & $0.36[0.21,0.60]$ & & & & \\
\hline Total events & 23 & & 54 & & & & & & & \\
\hline $\begin{array}{l}\text { Heterogeneity: } \mathrm{Chi}^{2} \text { - } \\
\text { Test for overall effect }\end{array}$ & $\begin{array}{l}4.97, d f=5(P \\
Z=3.89(P=0\end{array}$ & $\begin{array}{l}\text { 2); } 1^{2}=c( \\
\text { 1) }\end{array}$ & & & & & & $\begin{array}{cc}0.01 & 0.1 \\
\text { with drainage }\end{array}$ & 1 without drai & $\begin{array}{ll}10 & 100 \\
10 & \text { ainage system }\end{array}$ \\
\hline
\end{tabular}

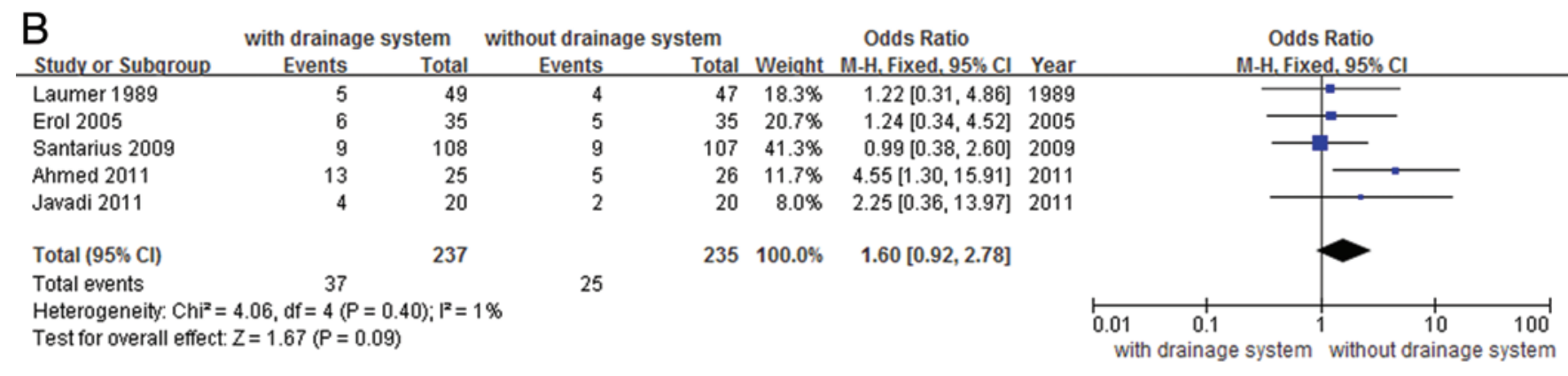

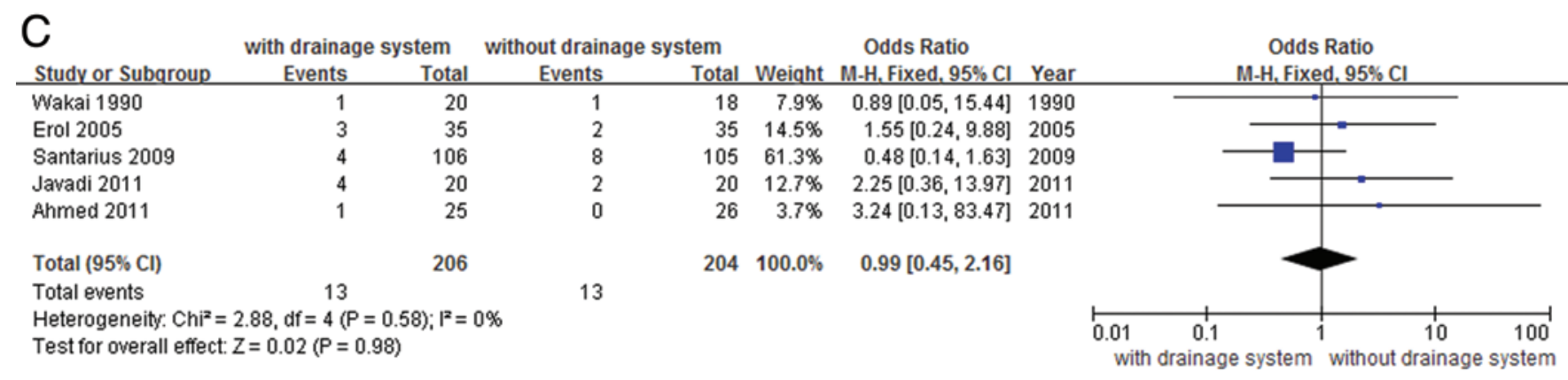

FIG. 3. Summary of the meta-analysis comparing the use of a closed drainage system in relation to recurrence of CSDH (A), complications (B), and mortality (C). Each horizontal line represents results of a single study. The square marks the OR estimate for the study and the size of the square is proportionate to the weight given to the information from the trial. The left and right endpoints of the horizontal line mark the ends of the $\mathrm{Cl}$ for the individual trial's OR estimate. In panel $\mathrm{A}$, the diamond represents the pooled estimate from the meta-analysis; its center lies on the left side, showing significant difference between 2 groups $(p<0.001)$.

out subgroup information. The other 5 studies were analyzed regarding complication rates. These 5 trials included 472 patients. There were 37 complications among 237 patients $(15.6 \%)$ with drainage system compared with 25 complications among 235 patients $(10.6 \%)$ without drainage. A fixed-effects meta-analysis showed a pooled OR of 1.60 (95\% CI 0.92-2.78; p = 0.09, Fig. 3B). No indication of heterogeneity between the results of the different trials was present $\left(\mathrm{p}=0.40 ; \mathrm{I}^{2}=1 \%\right)$.

Five studies (a total of 410 patients) could be analyzed for mortality. No significant differences were noted $(\mathrm{p}=0.98$, Fig. 3C). Outcome could not be analyzed because of different outcome measures and follow-up times of the included studies.

\section{Bur Hole Versus Twist Drill}

Four trials compared bur hole with twist drill procedures in CSDH (293 patients in total). Among these 4 studies, the twist procedures were different. Singh et al. ${ }^{32}$

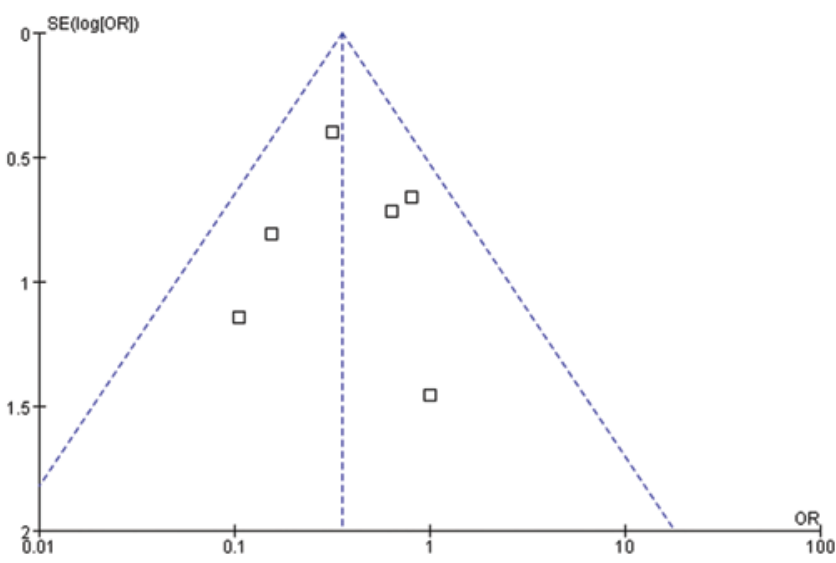

FIG. 4. A funnel plot evaluating publication bias in comparing with or without a closed drainage system in relation to recurrence of CSDH. The plot shows that the 6 included RCTs in this meta-analysis seem approximately symmetrically ranged around the overall effect size estimate, shown by the dashed line in the center. 
W. Liu, N. A. Bakker, and R. J. M. Groen

TABLE 2: The procedural differences among studies comparing twist drill and bur hole craniostomy

\begin{tabular}{|c|c|c|c|c|c|c|c|c|}
\hline \multirow[b]{2}{*}{ Authors \& Year } & \multirow[b]{2}{*}{ Type } & \multirow[b]{2}{*}{$\begin{array}{l}\text { No. of } \\
\text { Cases }\end{array}$} & \multicolumn{6}{|c|}{ Procedure } \\
\hline & & & $\begin{array}{c}\text { Type of } \\
\text { Anesthesia }\end{array}$ & $\begin{array}{l}\text { No. of } \\
\text { Holes }\end{array}$ & Irrigation & Catheter & $\begin{array}{l}\text { Drainage } \\
\text { System }\end{array}$ & Drainage Time \\
\hline Gökmen et al., 2008 & bur hole & 31 & $\begin{array}{l}\text { local or } \\
\text { general }\end{array}$ & 1 & yes & 12-Fr drain catheter & $\begin{array}{l}\text { bagged soft } \\
\text { drains }\end{array}$ & $\begin{array}{l}\text { remove } 2 \text { nd day of } \\
\text { surgery }\end{array}$ \\
\hline Horn et al., 2006 & bur hole & 24 & NR & 1 & yes & $\begin{array}{l}\text { ventriculostomy } \\
\text { catheter }\end{array}$ & NR & $\begin{array}{l}\text { blood adequately drained } \\
\quad \text { (on CT) }\end{array}$ \\
\hline \multirow[t]{2}{*}{ Muzii et al., 2005} & twist & 22 & local & 1 & no & $\begin{array}{l}\text { subdural expansion } \\
\text { catheter }\end{array}$ & $\begin{array}{l}100 \text {-ml suction } \\
\text { reservoir }\end{array}$ & $\begin{array}{l}\text { drainage ceased, average } \\
65.3 \mathrm{hrs}\end{array}$ \\
\hline & bur hole & 24 & local & 1 or 2 & yes & a catheter & $\begin{array}{l}50 \mathrm{~cm} \text { below } \\
\text { head }\end{array}$ & $\begin{array}{l}\text { drainage ceased average } \\
\quad 34.8 \mathrm{hrs}\end{array}$ \\
\hline
\end{tabular}

used 2 twist holes for drainage, Muzii et al. ${ }^{24}$ used 1 or 2 twist holes, and the other 2 trials used only 1 twist hole. Gökmen et al. ${ }^{7}$ and Muzii et al. ${ }^{24}$ did not use saline irrigation after twist hole procedures, while the other 2 trials did use irrigation. Three of 4 trials used a ventriculostomy catheter for drainage, while Muzii et al. ${ }^{24}$ used a subdural expansion catheter. Drainage time was also different: Gökmen et al. ${ }^{7}$ removed the catheter on the 2nd day after surgery, while Muzii et al. ${ }^{24}$ and Horn et al. ${ }^{11}$ removed the catheter when draining stopped. Singh et al. ${ }^{32}$ did not report on drainage time. The study by Horn et al. ${ }^{11}$ did not meet our predefined criteria for a clear definition of recurrence of hematoma. As such, this study was not used for the quantitative analysis. The procedural differences among included studies are shown in Table 2.

Because studies did not have a uniform operative procedure, study heterogeneity was analyzed, showing significant heterogeneity $\left(\mathrm{p}=0.11, \mathrm{I}^{2}=54 \%\right)$. As such, Mantel-Haenszel (M-H) random models were used to analyze recurrence rates between the 2 groups. The metaanalysis showed a pooled OR of 0.76 (95\% CI $0.26-2.25$; $\mathrm{p}=0.62$ [Fig. 5A]). Outcome was also defined in distinct ways among the included studies, leading to significant heterogeneity $\left(\mathrm{p}=0.20 ; \mathrm{I}^{2}=36 \%\right)$. Using $\mathrm{M}-\mathrm{H}$ random models, a pooled OR of 1.10 (95\% CI $0.60-2.00 ; p=0.76$ ) was observed (Fig. 5B). Regarding mortality, study heterogeneity was acceptable $\left(\mathrm{p}=0.28 \mathrm{I}^{2}=21 \%\right)$. The metaanalysis showed a pooled OR of 1.38 (95\% CI 0.55-3.43; $\mathrm{p}=0.49$ [Fig. 5C]). Complication rates could not be analyzed because too little information was provided in the studies included.

\section{Irrigation During the Operative Procedure}

Three of the included studies addressed irrigation during the procedure. ${ }^{8,13,37}$ These trials compared recurrence rates between studies using drainage with and without irrigation. Data on complications, outcome, and mortality were not available for analysis. These 3 trials included 254 patients. There were 9 recurrences among 112 patients $(8.0 \%)$ in the irrigation group compared with 20 recurrences among 142 patients $(14.1 \%)$ in the drainage without irrigation group. A fixed-effects meta-analysis showed a pooled OR of 0.49 (95\% CI 0.21-1.14; $\mathrm{p}=$ 0.10 [Fig. 6]).

\section{Postoperative Posture}

Abouzari et al. ${ }^{1}$ compared supine and sitting positions for 3 days postoperatively in a study with 84 patients. After follow-up of 3 months, the recurrence rate was $2.3 \%$ in the supine position group compared with $19.0 \%$ in the sitting position group. However, only 1 patient (1 [12.5\%] of 8 total patients in whom there were recurrences) needed a reoperation. According to definitions used in this review, only this case is considered a recurrence. Nakajima et al. ${ }^{26}$ did not find differences between postoperative positions. When analyzing the trials together, heterogeneity was acceptable $\left(\mathrm{p}=0.49 ; \mathrm{I}^{2}=0 \%\right)$, with a pooled OR of 0.86 (95\% CI 0.21-3.48; $\mathrm{p}=0.83$ [Fig. 7]).

\section{Position of Draining Catheter}

Two studies focused on the position of the catheter used for drainage. One trial was performed by Nakaguchi et al. ${ }^{25}$ The authors observed significantly fewer recurrences when the tip of the drain was placed in a frontal position (5\% recurrences) compared with the temporal (33\% recurrences), occipital (36\% recurrences), or parietal (38\% recurrences) position in a study with 63 patients. Another trial was performed by Kaliaperumal et al. ${ }^{18}$ In this prospective randomized study including 50 patients, 2 types of drainage were compared: subperiosteal drainage and subdural drainage following bur hole. No significant differences were detected.

\section{Duration of Drainage}

One trial including 65 patients could be included to 
Chronic SDH and surgical procedures

A

\begin{tabular}{|c|c|c|c|c|c|c|}
\hline & & & & & & \\
\hline Muzii 2005 & 1 & 22 & 5 & 24 & $60.4 \%$ & $0.18[0.02,1.69]$ \\
\hline Gökmen 2008 & 1 & 37 & 2 & 31 & $28.0 \%$ & $0.40[0.03,4.67]$ \\
\hline Singh 2011 & 4 & 48 & 1 & 52 & $11.6 \%$ & $4.64[0.50,43.04]$ \\
\hline Total $(95 \% \mathrm{Cl})$ & & 107 & & 107 & $100.0 \%$ & $0.76[0.26,2.25]$ \\
\hline Total events & 6 & & 8 & & & \\
\hline
\end{tabular}

B

\begin{tabular}{lrrrrr} 
B & \multicolumn{6}{c}{ twist } & \multicolumn{3}{c}{ bur hole } & \\
Study or Subgroup & Events & Total & Events & Total & Weight \\
\hline Muzii 2005 & 20 & 22 & 17 & 24 & $7.3 \%$ \\
Horn 2006 & 34 & 55 & 13 & 24 & $33.9 \%$ \\
Gökmen 2008 & 29 & 37 & 26 & 31 & $30.0 \%$ \\
Singh 2011 & 42 & 48 & 49 & 52 & $28.8 \%$ \\
& & & & & \\
Total (95\% Cl) & & 162 & & 131 & $100.0 \%$ \\
Total events & 125 & & 105 & &
\end{tabular}

Odds Ratio

M-H. Fixed, $95 \% \mathrm{Cl}$ Year

$4.12[0.75,22.52] 2005$

$1.37[0.52,3.61] 2006$

$0.70[0.20,2.40] 2008$

$0.43[0.10,1.82] 2011$

$1.10[0.60,2.00]$

Heterogeneity: $\mathrm{Chi}^{2}=4.67, \mathrm{df}=3(P=0.20) ; \mathrm{I}^{2}=36 \%$

Test for overall effect: $Z=0.30(P=0.76)$

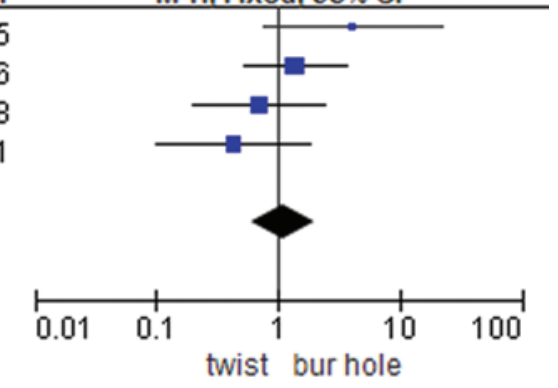

C

Study or Subqroup Events Total Events Total Weight M-H. Fixed. 95\% Cl Year

$\begin{array}{llllllrl}\text { Muzii 2005 } & 1 & 22 & 2 & 24 & 22.6 \% & 0.52[0.04,6.22] & 2005 \\ \text { Horn 2006 } & 4 & 55 & 3 & 24 & 48.0 \% & 0.55[0.11,2.67] & 2006 \\ \text { Gökmen 2008 } & 4 & 37 & 2 & 31 & 24.0 \% & 1.76[0.30,10.31] & 2008\end{array}$

$24.0 \%-1.76[0.30,10.31] 2008$

Singh 2011

448

$5.4 \% 10.62[0.56,202.65] 2011$

Total $(95 \% \mathrm{Cl})$

162

$131 \quad 100.0 \%$

$1.38[0.55,3.43]$

Total events 13 7

Heterogeneity: $\mathrm{Chi}^{2}=3.80, \mathrm{df}=3(P=0.28) ; \mathrm{I}^{2}=21 \%$

Test for overall effect: $Z=0.69(P=0.49)$

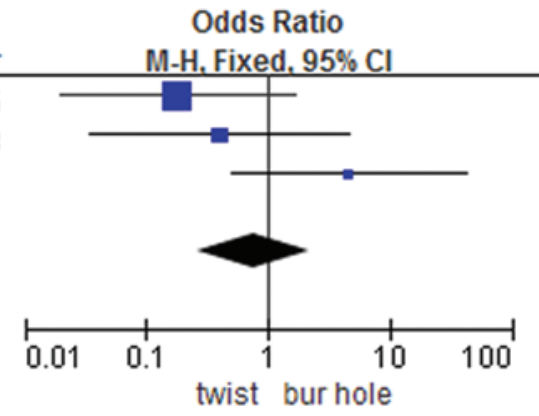

-H. Fixed, $95 \% \mathrm{Cl}$ 


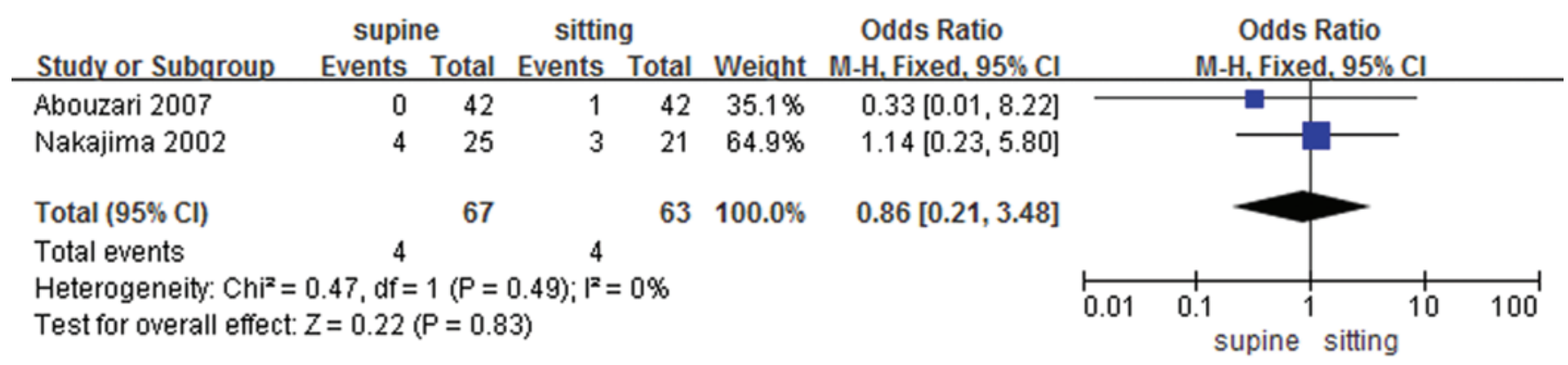

FIG. 7. Summary of the meta-analysis comparing the postoperative posture (supine vs sitting) in relation to recurrence of $\mathrm{CSDH}$. The diamond represents the pooled estimate from the meta-analysis; its centers lies on the left side, and it crosses the vertical line, showing no significant difference between the 2 groups $(p=0.83)$. There was no indication of heterogeneity between the results of the different trials $\left(p=0.49 ; l^{2}=0 \%\right)$.

\section{Discussion}

In recent years, a significant number of controlled trials were performed on different aspects of the surgical treatment of CSDH. Also, some meta-analyses were performed; ;,36 however, some questions on optimal treatment remain. As such, we aimed to perform a systematic review and meta-analysis of the available literature in a modern fashion, using the PRISMA statement, to provide clarity regarding the evidence for different aspects of surgical procedures to treat CSDH. In the present meta-analysis, it is clearly shown that postoperative drainage is useful in the treatment of CSDH. Drainage reduces recurrence by approximately $60 \%$, without an increase in complications and mortality. This is consistent with most neurosurgeons' experience in everyday clinical practice. As such, postoperative drainage should be recommended in the treatment of CSDH. Whether irrigation should be performed prior to postoperative drainage is less clear; recurrence rates were $8.0 \%$ in the irrigation group and $14.1 \%$ in the irrigationfree group $(\mathrm{p}=0.10)$. Although not significant, there was a trend in favor of irrigation. This makes sense in our opinion as this provides a washout of blood products and other factors possibly involved in maintaining the hematoma. In this respect, it has been shown that the hematoma fluid contains high concentrations of coagulation factors (plasminogen activator) ${ }^{14}$ and inflammatory factors (vascular endothelial growth factor), ${ }^{33}$ and both factors are shown to be predictive of recurrence. ${ }^{19,30}$ These mechanisms remain speculative, however.

There seemed to be no differences in results using a twist drill or a bur hole for hematoma drainage. It seems that the holes on the skull, being $5 \mathrm{~mm}$ (twist) or $10 \mathrm{~mm}$ (bur hole), are both sufficient for adequate drainage of the hematoma fluid.

Regarding postoperative posture, no definitive conclusions can be drawn from this review. Additional comparative studies are needed to find evidence in favor of one of the positions. Catheter location was only investigated by 2 studies. Although no overall differences were detected between subperiosteal drainage and subdural drainage, it was clearly shown that in case of subdural drainage, the catheter tip should be placed in the frontal position. Only 1 study investigated optimal drainage duration; it was shown that 48 hours of drainage instead of 96 hours led to significantly fewer complications. It is unclear, however, whether a shorter drainage time would also suffice.

Some limitations of this review have to be mentioned. Some of the included trials are quasi-(pseudo) RCTs, in which allocation took place by medical record number or the order of operation. Most of the studies did not report on random sequence generation and allocation concealment. Also, follow-up among the investigated trials varied. Unfortunately, in almost half of the included studies follow-up time was rather short, precluding us from drawing firm conclusions on outcome. Also, differences in recurrence and outcome criteria were present among studies, making it difficult to evaluate the results in a standardized way.

\section{Conclusions}

This review clearly demonstrates the benefit of postoperative drainage after treatment of CSDH. The use of irrigation seems to be beneficial, while both a twist drill and a bur hole seem to be reliable treatment options. As such, more studies addressing irrigation, duration of drainage, and postoperative position with uniform followup times of at least 6 months are needed.

\section{Disclosure}

The authors report no conflict of interest concerning the materials or methods used in this study or the findings specified in this paper.

Author contributions to the study and manuscript preparation include the following. Conception and design: Groen, Liu. Acquisition of data: Liu. Analysis and interpretation of data: Liu, Bakker. Drafting the article: Liu, Bakker. Critically revising the article: all authors. Reviewed submitted version of manuscript: all authors. Statistical analysis: Liu. Study supervision: Groen.

\section{References}

1. Abouzari M, Rashidi A, Rezaii J, Esfandiari K, Asadollahi $\mathrm{M}$, Aleali $\mathrm{H}$, et al: The role of postoperative patient posture in the recurrence of traumatic chronic subdural hematoma after burr-hole surgery. Neurosurgery 61:794-797, 2007

2. Ahmed S, Agrawal D, Kale SS, Mahapatra AK: A comparative study of treatment of chronic subdural hematoma - burr hole drainage versus continuous closed drainage. Indian J Neurotrauma 8:17-23, 2011 
3. Almenawer SA, Farrokhyar F, Hong C, Alhazzani W, Manoranjan B, Yarascavitch B, et al: Chronic subdural hematoma management: a systematic review and meta-analysis of 34,829 patients. Ann Surg 259:449-457, 2014

4. DerSimonian R, Laird N: Meta-analysis in clinical trials. Control Clin Trials 7:177-188, 1986

5. Erol FS, Topsakal C, Faik Ozveren M, Kaplan M, Tiftikci MT: Irrigation vs. closed drainage in the treatment of chronic subdural hematoma. J Clin Neurosci 12:261-263, 2005

6. Gai H: [Ultrasound of inguinal hernias: morphological classification for a potentially conservative treatment in asymptomatic patients.] Ultraschall Med 31:258-263, 2010 (Ger)

7. Gökmen M, Sucu HK, Ergin A, Gökmen A, Bezirciodlu H: Randomized comparative study of burr-hole craniostomy versus twist drill craniostomy; surgical management of unilateral hemispheric chronic subdural hematomas. Zentralbl Neurochir 69:129-133, 2008

8. Gurelik M, Aslan A, Gurelik B, Ozum U, Karadag O, Kars HZ: A safe and effective method for treatment of chronic subdural haematoma. Can J Neurol Sci 34:84-87, 2007

9. Higgins JP, Altman DG, Gøtzsche PC, Jüni P, Moher D, Oxman AD, et al: The Cochrane Collaboration's tool for assessing risk of bias in randomised trials. BMJ 343:d5928, 2011

10. Hirashima Y, Kurimoto M, Nagai S, Hori E, Origasa H, Endo $S$ : Effect of platelet-activating factor receptor antagonist, etizolam, on resolution of chronic subdural hematoma-a prospective study to investigate use as conservative therapy. Neurol Med Chir (Tokyo) 45:621-626, 2005

11. Horn EM, Feiz-Erfan I, Bristol RE, Spetzler RF, Harrington TR: Bedside twist drill craniostomy for chronic subdural hematoma: a comparative study. Surg Neurol 65:150-154, 2006

12. Ibrahim I, Maarrawi J, Jouanneau E, Guenot M, Mertens P, Sindou M: [Evacuation of chronic subdural hematomas with the Twist-Drill technique: Results of a randomized prospective study comparing 48-h and 96-h drainage duration.] Neurochirurgie 56:23-27, $2010(\mathrm{Fr})$

13. Ishibashi A, Yokokura Y, Adachi H: A comparative study of treatments for chronic subdural hematoma: burr hole drainage versus burr hole drainage with irrigation. Kurume Med J 58:35-39, 2011

14. Ito H, Saito K, Yamamoto S, Hasegawa T: Tissue-type plasminogen activator in the chronic subdural hematoma. Surg Neurol 30:175-179, 1988

15. Javadi A, Amirjamshidi A, Aran S, Hosseini SH: A randomized controlled trial comparing the outcome of burr-hole irrigation with and without drainage in the treatment of chronic subdural hematoma: a preliminary report. World Neurosurg 75:731-736, 620-623, 2011

16. Jennett B, Bond M: Assessment of outcome after severe brain damage. Lancet 1:480-484, 1975

17. Johnson ML, Gordon HS, Petersen NJ, Wray NP, Shroyer AL, Grover FL, et al: Effect of definition of mortality on hospital profiles. Med Care 40:7-16, 2002

18. Kaliaperumal C, Khalil A, Fenton E, Okafo U, Kaar G, O'Sullivan M, et al: A prospective randomised study to compare the utility and outcomes of subdural and subperiosteal drains for the treatment of chronic subdural haematoma. Acta Neurochir (Wien) 154:2083-2089, 2012

19. Katano H, Kamiya K, Mase M, Tanikawa M, Yamada K: Tissue plasminogen activator in chronic subdural hematomas as a predictor of recurrence. J Neurosurg 104:79-84, 2006

20. Kitakami A, Ogawa A, Hakozaki S, Kidoguchi J, Obonai C, Kubo N: Carbon dioxide gas replacement of chronic subdural hematoma using single burr-hole irrigation. Surg Neurol 43:574-578, 1995

21. Kudo H, Kuwamura K, Izawa I, Sawa H, Tamaki N: Chronic subdural hematoma in elderly people: present status on Awaji Island and epidemiological prospect. Neurol Med Chir (Tokyo) 32:207-209, 1992
22. Kuroki T, Katsume M, Harada N, Yamazaki T, Aoki K, Takasu $\mathrm{N}$ : Strict closed-system drainage for treating chronic subdural haematoma. Acta Neurochir (Wien) 143:1041-1044, 2001

23. Laumer R, Schramm J, Leykauf K: Implantation of a reservoir for recurrent subdural hematoma drainage. Neurosurgery 25:991-996, 1989

24. Muzii VF, Bistazzoni S, Zalaffi A, Carangelo B, Mariottini A, Palma L: Chronic subdural hematoma: comparison of two surgical techniques. Preliminary results of a prospective randomized study. J Neurosurg Sci 49:41-47, 2005

25. Nakaguchi $H$, Tanishima $T$, Yoshimasu N: Relationship between drainage catheter location and postoperative recurrence of chronic subdural hematoma after burr-hole irrigation and closed-system drainage. J Neurosurg 93:791-795, 2000

26. Nakajima $H$, Yasui $T$, Nishikawa M, Kishi H, Kan M: The role of postoperative patient posture in the recurrence of chronic subdural hematoma: a prospective randomized trial. Surg Neurol 58:385-387, 2002

27. Ram Z, Hadani M, Sahar A, Spiegelmann R: Continuous irrigation-drainage of the subdural space for the treatment of chronic subdural haematoma. A prospective clinical trial. Acta Neurochir (Wien) 120:40-43, 1993

28. Santarius T, Kirkpatrick PJ, Ganesan D, Chia HL, Jalloh I, Smielewski P, et al: Use of drains versus no drains after burr-hole evacuation of chronic subdural haematoma: a randomised controlled trial. Lancet 374:1067-1073, 2009

29. Shimamura N, Ogasawara Y, Naraoka M, Ohnkuma H: Irrigation with thrombin solution reduces recurrence of chronic subdural hematoma in high-risk patients: preliminary report. J Neurotrauma 26:1929-1933, 2009

30. Shono T, Inamura T, Morioka T, Matsumoto K, Suzuki SO, Ikezaki K, et al: Vascular endothelial growth factor in chronic subdural haematomas. J Clin Neurosci 8:411-415, 2001

31. Sindou M, Ibrahim I, Maarrawi J: Chronic sub-dural hematomas: twist drill craniostomy with a closed system of drainage, for 48 hours only, is a valuable surgical treatment. Acta Neurochir (Wien) 152:545-546, 2010

32. Singh SK, Sinha M, Singh VK, Parihar A, Srivastava C, Ojha BK, et al: A randomized study of twist drill versus burr hole craniostomy for treatment of chronic subdural hematomas in 100 patients. Indian J Neurotrauma 8:83-88, 2011

33. Suzuki K, Takano S, Nose T, Doi M, Ohashi N: Increased concentration of vascular endothelial growth factor (VEGF) in chronic subdural hematoma. J Trauma 46:532-533, 1999

34. Tsutsumi K, Maeda K, Iijima A, Usui M, Okada Y, Kirino $\mathrm{T}$ : The relationship of preoperative magnetic resonance imaging findings and closed system drainage in the recurrence of chronic subdural hematoma. J Neurosurg 87:870-875, 1997

35. Wakai S, Hashimoto K, Watanabe N, Inoh S, Ochiai C, Nagai M: Efficacy of closed-system drainage in treating chronic subdural hematoma: a prospective comparative study. Neurosurgery 26:771-773, 1990

36. Weigel R, Schmiedek P, Krauss JK: Outcome of contemporary surgery for chronic subdural haematoma: evidence based review. J Neurol Neurosurg Psychiatry 74:937-943, 2003

37. Zakaraia AM, Adnan JS, Haspani MS, Naing NN, Abdullah JM: Outcome of 2 different types of operative techniques practiced for chronic subdural hematoma in Malaysia: an analysis. Surg Neurol 69:608-616, 2008

Manuscript submitted December 10, 2013.

Accepted May 27, 2014.

Please include this information when citing this paper: published online July 4, 2014; DOI: 10.3171/2014.5.JNS132715.

Address correspondence to: Rob J. M. Groen, M.D., Ph.D., Department of Neurosurgery AB71, University Medical Center Groningen, P. O. Box 30.001, Groningen 9700 RB, the Netherlands. email: r.j.m.groen@umcg.nl. 